\title{
Pax6 Is Required at the Telencephalic Pallial-Subpallial Boundary for the Generation of Neuronal Diversity in the Postnatal Limbic System
}

\author{
Laura A. Cocas, ${ }^{1,2,3}$ Petrina A. Georgala, ${ }^{4}$ Jean-Marie Mangin, ${ }^{1}$ James M. Clegg, ${ }^{4}$ Nicoletta Kessaris, ${ }^{5,6}$ Tarik F. Haydar, ${ }^{1,7}$ \\ Vittorio Gallo, ${ }^{1}$ David J. Price, ${ }^{4}$ and Joshua G. Corbin ${ }^{1}$ \\ ${ }^{1}$ Center for Neuroscience Research, Children's Research Institute, Children's National Medical Center, Washington, DC 20010, ${ }^{2}$ Interdisciplinary Program in \\ Neuroscience, Georgetown University Medical Center, Washington, DC 20007, ${ }^{3}$ Department of Cell Biology, Biozentrum, University of Basel, CH-4056 Basel, \\ Switzerland, ${ }^{4}$ Genes and Development Group, Centre for Integrative Physiology, School of Biomedical Sciences, The University of Edinburgh, Edinburgh EH8 9XD, \\ United Kingdom, ${ }^{5}$ Wolfson Institute for Biomedical Research and ${ }^{\circ}$ Department of Cell and Developmental Biology, University College London, London WC1E 6BT, \\ United Kingdom, and ${ }^{7}$ Department of Anatomy and Neurobiology, Boston University School of Medicine, Boston, Massachusetts 02118
}

During embryogenesis, the pallial-subpallial boundary (PSB) divides the two main progenitor domains in the telencephalon: the pallium, the major source of excitatory neurons, and the subpallium, the major source of inhibitory neurons. The PSB is formed at the molecular interface between the pallial (high Pax6+) and subpallial (high Gsx2+) ventricular zone (VZ) compartments. Initially, the PSB contains cells that express both Pax6 and Gsx2, but during later stages of development this boundary is largely refined into two separate compartments. In this study we examined the developmental mechanisms underlying PSB boundary formation and the postnatal consequences of conditional loss of Pax6 function at the PSB on neuronal fate in the amygdala and olfactory bulb, two targets of PSB-derived migratory populations. Our cell fate and time-lapse imaging analyses reveal that the sorting of Pax6 + and Gsx2+ progenitors during embryogenesis is the result of a combination of changes in gene expression and cell movements. Interestingly, we find that in addition to giving rise to inhibitory neurons in the amygdala and olfactory bulb, Gsx2+ progenitors generate a subpopulation of amygdala excitatory neurons. Consistent with this finding, targeted conditional ablation of Pax6 in Gsx2+ progenitors results in discrete local embryonic patterning defects that are linked to changes in the generation of subsets of postnatal excitatory and inhibitory neurons in the amygdala and inhibitory neurons in the olfactory bulb. Thus, in PSB progenitors, Pax6 plays an important role in the generation of multiple subtypes of neurons that contribute to the amygdala and olfactory bulb.

\section{Introduction}

The amygdala and olfactory bulb (OB) are ancient structures that are contained within the relatively evolutionarily youthful mammalian forebrain. Both are important components of limbic system circuits that process memory and respond to fear and fear

Received July 24, 2010; revised Dec. 20, 2010; accepted Jan. 17, 2011.

This work was supported by the following: National Institutes of Health (NIH) Grant R01 NIDA020140 (J.G.C.), National Research Service Award predoctoral fellowship and NIH Grant NS564662 (L.A.C.), the Cellular Imaging Core of Mental Retardation and Developmental Disabilities Research Center (P30HD40677), The Wellcome Trust 08420 (D.J.P.), The Medical Research Council Grants 0800429 (D.J.P.) and 75618 (N.K.), and the European Research Council Grant 207807 (N.K.). L.A.C. and J.G.C. designed, planned, and interpreted the experiments and wrote the manuscript. Conceptual input was also provided by D.J.P. L.A.C. performed all of the experiments, analyses, and figure preparation except as follows: P.A.G., under the direction of D.J.P., completed the Ngn2 immunostaining and, in coordination with L.A.C, embryonic in situ experiments as well as provided genotyped conditional knock-out tissues. J.-M.M., under the direction of V.G., and L.A.C. performed the patch-clamp experiments and analysis. J.M.C., under the direction of D.J.P., performed the embryonic Pax6 DAB immunostaining and Dbx1 in situ hybridization. N.K. provided genotyped Gsx2 ${ }^{\text {Cre }}$ embryonic brains and Gsx2 ${ }^{\text {Cre }}$ mice. L.A.C. performed the time-lapse experiments with training and guidance from T.F.H. We thank the following people for sharing of reagents: K. Campbell for the Gsx2 antibody, R. Hevner for the Tbr1 antibody, V. van Heyningen for the Pax6 antibody, and K. Yoshikawa for the pan-Dlx antibody. Wethank R. Carney for contribution of select in situ hybridization probes and Martine Manuel for perfusing several $\mathrm{Pax} 6^{\mathrm{CKO}}$ mice. Wealso thank the following people for their critical comments and reading of the manuscript: Jose Luis Olmos-Serrano, Judy Liu, Molly Huntsman, and Irene Zohn.

Correspondence should be addressed to Joshua G. Corbin, Center for Neuroscience Research, Children's Research Institute, Children's National Medical Center, 111 Michigan Avenue NW, Washington, DC 20010. E-mail: jcorbin@cnmcresearch.org.

DOI:10.1523/JNEUROSCI.3867-10.2011

Copyright $\odot 2011$ the authors $\quad 0270-6474 / 11 / 315313-12 \$ 15.00 / 0$ extinction; their dysfunction has also been implicated in several human disorders, including autism spectrum disorders (Rodrigues et al., 2004; Amaral et al., 2008; Herry et al., 2008; Markram et al., 2008; Monk, 2008). Unraveling the genetic and cellular mechanisms of development of these interconnected brain structures is therefore necessary to understand function and dysfunction of the adult forebrain.

Previous studies have revealed that major neuronal subpopulations in the amygdala and $\mathrm{OB}$ are derived from the pallialsubpallial boundary (PSB), a transient molecular border where telencephalic pallial and subpallial gene expression meet (Toresson et al., 2000; Yun et al., 2001; Corbin et al., 2003; Carney et al., 2006, 2009). PSB progenitors give rise to subsets of interneurons in the $\mathrm{OB}$ via the rostral migratory stream, and to amygdala basolateral complex (BLC) excitatory and intercalated cell mass (ICM) inhibitory neurons via the lateral cortical stream (LCS) (Stenman et al., 2003a; Carney et al., 2006; Likhtik et al., 2008; Lledo et al., 2008; Hirata et al., 2009; Waclaw et al., 2009, 2010; Kaoru et al., 2010).

The PSB is characterized by the convergence of expression of Pax6 in the ventral pallium (vP) and Gsx2 in the dorsal lateral ganglionic eminence (dLGE) (Toresson et al., 2000; Yun et al., 2001; Corbin et al., 2003; Carney et al., 2006, 2009). Analyses of 
mouse mutants have revealed that Pax6 and Gs $x 2$ function in a cross-repressive and combinatorial manner for proper PSB patterning (Mastick et al., 1997; Corbin et al., 2000; Toresson et al., 2000; Yun et al., 2001; Nomura et al., 2006; Carney et al., 2009). During embryogenesis, Pax6 and Gsx2 expression patterns at the PSB are dynamic, initially overlapping at embryonic day 10.5 (E10.5), with subsequent refinement by midneurogenesis into two largely separate compartments (Corbin et al., 2003). However, the cellular mechanisms that regulate the sorting of progenitors to their respective compartments and the link between the genetic regulation of PSB patterning and the generation of neuronal diversity in the amygdala and the $\mathrm{OB}$ remain unexplored.

In this study we used genetic fate mapping and conditional mutagenesis to address these questions. We found that the molecular refinement of the PSB is a dynamic process regulated by changes in gene expression and cell movements. Further, Gsx2lineage cells generate multiple inhibitory interneuron subtypes in the $\mathrm{OB}$ and BLC and, surprisingly, a subpopulation of BLC excitatory neurons. Moreover, conditional ablation of Pax6 at the PSB results in focal defects in embryonic patterning that correspond to alterations in the generation of multiple neuronal subpopulations in the postnatal $\mathrm{OB}$ and amygdala. Thus, the formation and maintenance of the PSB by Pax6 and Gs 22 is not only important for the correct patterning of progenitor domains during embryonic development; it is also critical for the establishment of specific excitatory and inhibitory neuronal subpopulations in the postnatal limbic system.

\section{Materials and Methods}

Animal use. Swiss Webster (Taconic Farms), ROSA-YFP (The Jackson Laboratory), Gs $x 2^{\text {Cre }}$ (N. Kessaris, University College London, London, UK) (Kessaris et al., 2006), Pax6-GFP (GENSAT) (Gong et al., 2003), and Pax6 $^{\text {flox/flox }}$ (D. Price, University of Edinburgh, Edinburgh, UK) (Simpson et al., 2009) mice used in these studies were maintained according to the protocols approved by Children's National Medical Center and the University of Edinburgh. Gs $x 2^{C r e}$ and $P a x 6^{\text {flox/flox }}$ mice were maintained on a mixed C57BL/ $6 \times$ SW background at Children's National Medical Center; Pax $6^{\text {flox/flox }}$ and Gsx $2^{\text {Cre; }}$ RYFP; Pax $6^{\text {flox/flox }}$ mice were maintained on C57BL/ 6 background at the University of Edinburgh. For staging of the embryos, midday of vaginal plug detection was considered as E0.5. For postnatal animals, the day of birth was considered as postnatal day 0 (P0). The genotyping of animals was performed as described previously (Carney et al., 2009; Simpson et al., 2009). Gs $\times 2^{\mathrm{Cre}^{+/-}}$; $\mathrm{Pax6}^{+/+}$; ROSA-YFP ${ }^{+/-}$were used as controls, while Gs $x 2^{\mathrm{Cre}^{+/-}}$; $\mathrm{Pax}^{\mathrm{c} / c}$; $\mathrm{ROSA}^{-}$ $\mathrm{YFP}^{+/-}$(herein referred to as $\mathrm{Pax}^{\mathrm{cKO}}$ ) mice were used for analysis of conditional knock-outs.

Tissue preparation and histology. For immunofluorescence and in situ hybridization at embryonic ages, brains were fixed in $4 \%$ paraformaldehyde (PFA) for $2 \mathrm{~h}$ or overnight, respectively. Brains were cryoprotected by sucrose immersion, embedded in Histoprep (Fisher Scientific) and frozen. Serial coronal sections of embedded tissue were cut at 20-30 $\mu \mathrm{m}$ thickness using a cryostat and mounted on glass slides. Postnatal animals were transcardially perfused at P21 with $4 \%$ PFA, postfixed for 2-4 h, and processed in the same manner as the embryonic tissue.

Immunohistochemistry. Cryostat mounted sections were air dried and rinsed three times in PBS before blocking for $1 \mathrm{~h}$ in 10\% normal donkey serum diluted in PBS with $0.2 \%$ Triton to prevent nonspecific binding. Primary antibodies were diluted in $1 \%$ serum diluted in PBS with $0.2 \%$ Triton; sections were incubated in primary antibody overnight at $4^{\circ} \mathrm{C}$. The primary antibodies used were as follows: goat anti-Pax6 (1:200; Santa Cruz Biotechnology), rabbit anti-Pax6 (gift from V. van Heyningen, Western General Hospital, Edinburgh, UK), mouse anti-NeuN (1: 500; Covance), rat anti-GFP (1:2000; Nacalai), rabbit anti-Gsx2 (1:1500; gift from K. Campbell, University of Cincinnati College of Medicine, Cincinnati, OH), rabbit anti-Tbr1 (1:1000; gift from R. Hevner, University of Washington, Seattle, WA), guinea-pig anti-panDlx (1:1500; gift from K. Yoshikawa, Osaka University, Suita, Japan), rabbit anti-tyrosine hydroxylase (TH) (1:1000; Millipore Bioscience Research Reagents), rabbit anti-Mef2c (1:1000; ProteinTech Group), rat anti-somatostatin (1: 1000; Millipore), rabbit anti-parvalbumin (1:1000; Swant), rabbit anticalbindin (1:1000; Sigma), and rabbit anti-calretinin (1:2000; Swant). To detect primary antibodies, secondary antibodies raised in mouse, rat, goat, guinea pig, and rabbit were used (Cy3 and Cy5 at 1:200, FITC at 1:50; all from Jackson ImmunoResearch Laboratories). Sections were incubated for $2 \mathrm{~h}$ in $1 \%$ serum in PBS with $0.2 \%$ Triton and were washed and coverslipped with gel mount (Sigma) or Vectashield with DAPI (Vector Laboratories).

In situ hybridization. Tissue was prepared as described above. Nonradioactive dioxygenin-labeled RNA in situ hybridization was performed as described previously (Carney et al., 2009). The probes used in this study were Islt1, Ngn2, Tsh1, Sp8, Sfrp2, Dbx1, Dlx1/2, and Er81.

Time-lapse imaging. Time-lapse imaging experiments were performed as described previously (Gal et al., 2006). Briefly, E11.5 and E13.5 brains were dissected in ice-cold HBSS (Invitrogen), the skull and meninges were removed, and brains were placed in 3\% low melt agarose (Fisher Scientific). Slices (250-300 $\mu \mathrm{m})$ were cut using a vibratome (VT1000S; Leica), and sections were allowed to recover at $37^{\circ} \mathrm{C}$ in MEM supplemented with L-glutamine (1:100), penicillin/streptomycin (1:100), and $10 \%$ fetal bovine serum (all from Invitrogen). Slices were then mounted on an inverse Zeiss LSM 510 confocal microscope mounted with a custom-made incubation chamber and perfusion system. Slices were continuously perfused with Neurobasal medium supplemented with B27, N2, penicillin/streptomycin, L-glutamine, and $\mathrm{CO}_{2}$ and maintained at $37^{\circ} \mathrm{C} . Z$-stack images of GFP + cells were taken using a Coherent Mira $900 \mathrm{~F}$ multiphoton laser scanning at $790 \mathrm{~nm}$ every $6 \mathrm{~min}$ for $16-21 \mathrm{~h}$. The time series $Z$-stacks were compiled and processed using Velocity imaging software. For analysis of cell movements, ImageJ cell tracking software was used to calculate distance traveled and velocity of individual cells.

Electrophysiology. Electrophysiological recordings were performed from fluorescent Gsx2-lineage YFP+ cells located in the lateral nucleus of the amygdala. Briefly, animals were deeply anesthetized (with isoflurane) until nonresponsive and then decapitated. Brains were removed and immediately immersed for 2-3 $\mathrm{min}$ in an ice-cold oxygenated $(95 \%$ $\mathrm{O}_{2} / 5 \% \mathrm{CO}_{2}$ ) sucrose slicing solution: (in $\mathrm{mm}$ ) $87 \mathrm{NaCl}, 2.5 \mathrm{KCl}, 1.25$ $\mathrm{NaH}_{2} \mathrm{PO}_{4}, 7 \mathrm{MgCl}_{2}, 0.5 \mathrm{CaCl}_{2}, 25 \mathrm{NaHCO}_{3}, 25$ glucose, and 75 sucrose (347 mOsmol) at $\mathrm{pH}$ 7.4. Coronal slices containing the amygdala were cut on a vibratome (VT1000S, Leica) at $250 \mu \mathrm{m}$. Slices were collected and placed in a clean chamber containing oxygenated sucrose slicing solution at room temperature and incubated for $1 \mathrm{~h}$, then transferred to a chamber containing oxygenated artificial CSF (ACSF): (in mM) $119 \mathrm{NaCl}, 26$ $\mathrm{NaHCO}_{3}, 10$ glucose, $2.5 \mathrm{KCl}, 1.25 \mathrm{NaH}_{2} \mathrm{PO}_{4} \cdot \mathrm{H}_{2} \mathrm{O}, 1.3 \mathrm{MgSO}_{4}$, and 2.5 $\mathrm{CaCl}_{2} \cdot 2 \mathrm{H}_{2} \mathrm{O} ; \mathrm{pH} 7.4$, room temperature. Neurons were located and visualized with a fixed-stage, upright microscope (BX51WI, Olympus) equipped with a $4 \times$ objective and a $63 \times$ insulated objective, infrared (IR) illumination, Nomarski optics, an IR-sensitive video camera (Oly150), and a fluorescent lamp. Glass pipettes (borosilicate glass with filament, WPI) were pulled with an upright micropipette puller (PP 830, Narishige) to a resistance of 3-6 M $\Omega$. For all recordings, the intracellular pipette solution consisted of the following (in mM): $130 \mathrm{~K}$-gluconate, 20 $\mathrm{KCl}, 10$ HEPES, 0.1 EGTA, $2 \mathrm{MgCl}_{2}, 2 \mathrm{Na}_{2} \mathrm{ATP}, 0.4 \mathrm{NaGTP}$, and $3 \mathrm{mg} / \mathrm{ml}$ biocytin ( $\mathrm{pH}$ adjusted to $7.2,290 \mathrm{mOsmol}$ ). Recordings were performed at room temperature with continuous perfusion $(2 \mathrm{ml} / \mathrm{min})$ of ACSF. Cells were recorded in current-clamp mode using a multiclamp 700B amplifier (Molecular Devices) and a Digidata 1322A acquisition system (Molecular Devices) connected to a PC running pClamp 9.2 (Molecular Devices). For all cells, membrane potential and input resistance values were recorded. Cells were then characterized on the response to depolarizing and hyperpolarizing current pulses for a duration of $1000 \mathrm{~ms}$ in 16 consecutive sweeps. Off-line analysis was performed using Clampfit 9.2 (Molecular Devices). In all experiments, data were filtered at $10 \mathrm{kHz}$ during capacitance compensation and $5 \mathrm{kHz}$ during subsequent data recording. The traces were digitized at $10 \mathrm{kHz}$. All voltage measurements and steps were corrected for a junction potential offset.

Microscopy. In situ hybridization photographs were taken using an Olympus BX51 microscope. Fluorescent photographs were taken using a 


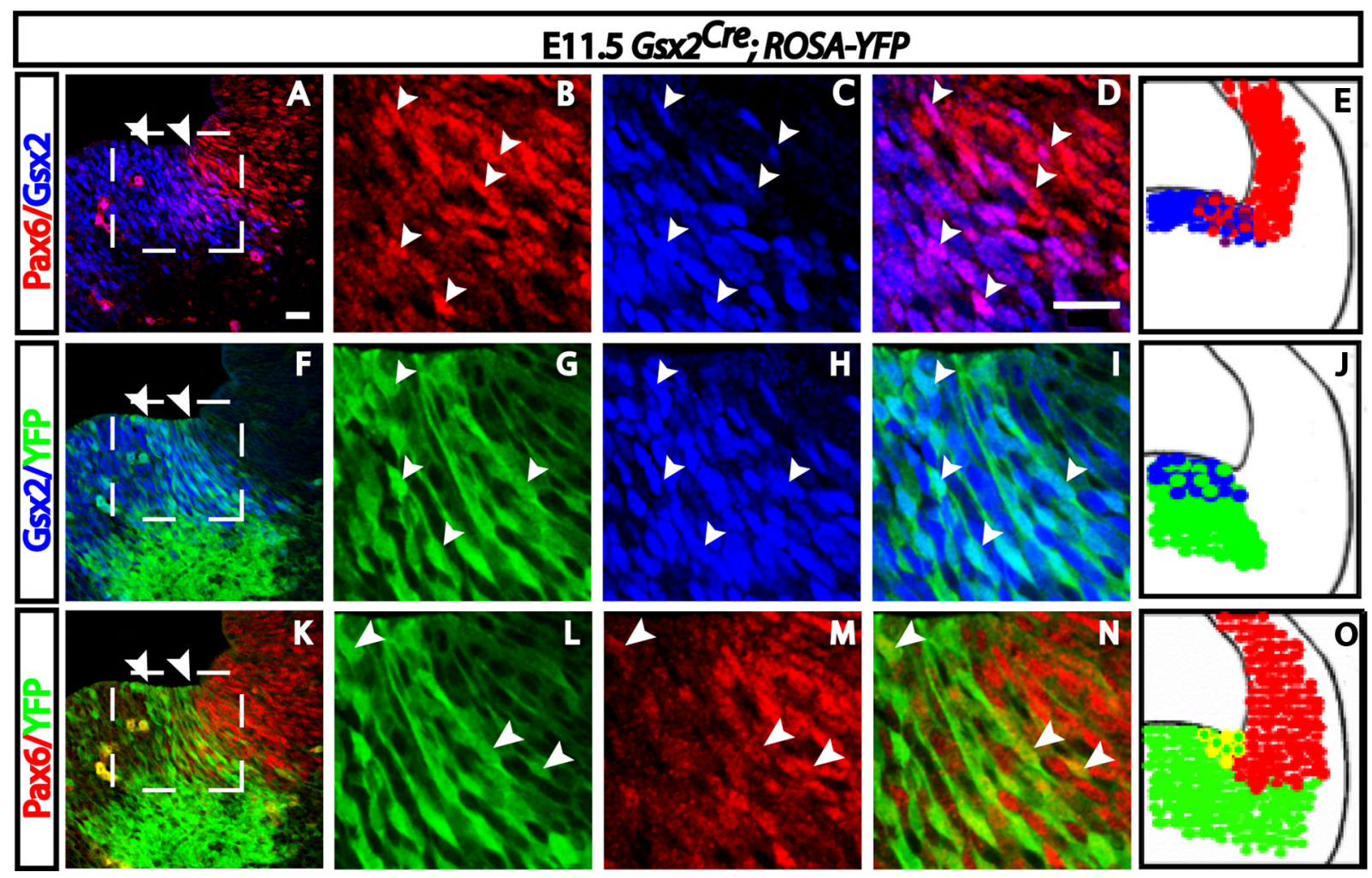

Figure 1. The PSB at E11.5 is a mixed domain. $A, \operatorname{In} G s \times 2{ }^{\text {Cre }} ;$ ROSA-YFP embryos, Pax6 and GsX2 protein expression overlaps in the ventricular zone at the PSB. Arrowheads delineate the region of Pax6-Gsx2 overlap. $\boldsymbol{B}-\boldsymbol{D}$, Higher magnification of boxed area in $\boldsymbol{A}[\operatorname{Pax6}(\boldsymbol{B}), G s \times 2(\boldsymbol{C})$, and overlay $(\boldsymbol{D})]$ illustrates intermingling of Pax6 + and Gsx2 + cells, along with a population that express both Pax6 and Gsx2 (arrowheads). $\boldsymbol{E}$, Schematic illustrates Pax6 and Gsx2 overlap. $\boldsymbol{F}$, YFP expression marks Gsx2-lineage cells with faithful recapitulation of Gsx2 protein expression; not all cells are recombined at this early age. Arrowheads reference the boundary of overlap of Pax6 and Gsx2 in $\boldsymbol{A}$. G-I, Higher magnification of boxed area in $\boldsymbol{F}[$ YFP $(\boldsymbol{G})$, Gsx2 (H), and overlay $(\boldsymbol{I})]$ shows double YFP +/GsX2 + cells. Arrowheads mark the edge of the YFP and Gsx2 protein domains. J, Schematic illustrates YFP and Gsx2 expression. $\boldsymbol{K}$, Pax6 and YFP expression overlap at the PSB. Arrowheads delineate the region of overlap. $\boldsymbol{L}-\boldsymbol{N}$, Higher magnification of boxed area in $\boldsymbol{K}[\mathrm{YFP}(\boldsymbol{L})$, Pax6 $(\boldsymbol{M})$, and overlay $(\boldsymbol{N})]$ shows Pax $6+/ \mathrm{YFP}+$ cells in the PSB domain. Arrowheads mark Pax6 $+/$ YFP + cells. $\boldsymbol{O}$, Schematic illustrates Pax6 and YFP expression. All images are taken from triple immunostaining of the same section, representative of sections from $N=4$ brains. Scale bars: $\boldsymbol{A}$ (for $\boldsymbol{A}, \boldsymbol{F}, \boldsymbol{K}$ ), D (for $B-D, G-I, L-N), 25 \mu \mathrm{m}$.

Zeiss LSM 510 confocal microscope. For confocal image analysis, each fluorophore was scanned sequentially and $Z$-stacks of the images obtained were collapsed into a single projection image or presented as individual optical sections. Figures were prepared using ImageJ and Adobe Illustrator; brightness and contrast adjustments were applied equally across all images.

Data analysis. Postnatal sections from Gs $x 2^{\mathrm{Cre}} ; \mathrm{Pax}^{+/+}$; ROSA-YFP and Gs $x 2^{\mathrm{Cre}}$; Paxf $6^{\text {flox/flox }}$; ROSA-YFP brains were photographed as described above. For each immunohistochemical marker, coronal sections of the lateral and basolateral amygdala at bregma levels -1.6 to -2.4 and of the olfactory bulb at bregma levels 3.5 to 4.3 were examined from $n \geq$ 3 control and $\operatorname{Pax}^{c K O}$ brains. The following criteria were applied to determine colocalization of cell-subtype markers with YFP fluorescence: (1) Cells were counted from individual optical sections, not collapsed projection images. (2) Cells were counted as double positive if an immunopositive YFP cell body was clearly colocalized with the fluorophore of interest and contained a nucleus that was also DAPI-positive. All statistical analyses of differences between groups were conducted using a two-tailed type 2 Student's $t$ test, and the null hypothesis was rejected if $p<0.05$.

\section{Results}

\section{Mechanisms of PSB refinement}

The PSB is a region in the ventricular zone of the developing telencephalon where high pallial-expressed Pax6 in the vP converges with high subpallial-expressed Gs $x 2$ in the dLGE (Toresson et al., 2000; Yun et al., 2001; Corbin et al., 2003; Carney et al., 2006, 2009). In addition, our previous work has revealed that at the onset of Gsx2 expression (27 somites, $\sim \mathrm{E} 10.0)$, Gsx2 and
Pax6 expression intermingles, and this overlap is largely resolved by 3-4 d later (Corbin et al., 2003). However, how this molecular border is refined remains unexplored. Therefore, we sought to further investigate the timing and the cellular mechanisms underlying PSB refinement. Previous studies of boundary refinement in other brain regions indicate that there are two main non-mutually-exclusive mechanisms by which this may occur: (1) Cells expressing patterning genes not shared by their neighbor cells downregulate the "incorrect" genes and upregulate the "correct" genes expressed by their neighbors. (2) Cells expressing patterning genes not shared by neighboring cells move into the territory of like-expressing cells.

To explore whether PSB VZ progenitor cells change gene expression during the period of PSB refinement, we indelibly labeled Gsx2-expressing progenitors and their descendants in Gsx2 ${ }^{\text {Cre }}$; ROSA-YFP embryos (Kessaris et al., 2006). Thus, by analysis of Gsx2+, Pax6+, and YFP+ (Gsx2-lineage) cells during the window of PSB refinement, we were able to determine whether Gsx2+ cells changed their fate to express Pax6+. Consistent with work from our laboratory and others (Yun et al., 2001; Corbin et al., 2003), we found that at E11.5, the PSB is a mixed boundary, with Pax6 + cells present in the Gsx2+ domain, and Gsx2+ cells present in the Pax6+ domain; a subpopulation of cells also express both Pax6 and Gsx2 (Fig. 1A,B). At earlier embryonic ages, YFP+ (Gsx2-lineage) cells in the more ventral aspect of the PSB (dLGE) largely coexpress Gsx2 protein (Fig. $1 C, D)$. Additionally, a subpopulation of YFP + cells also express 


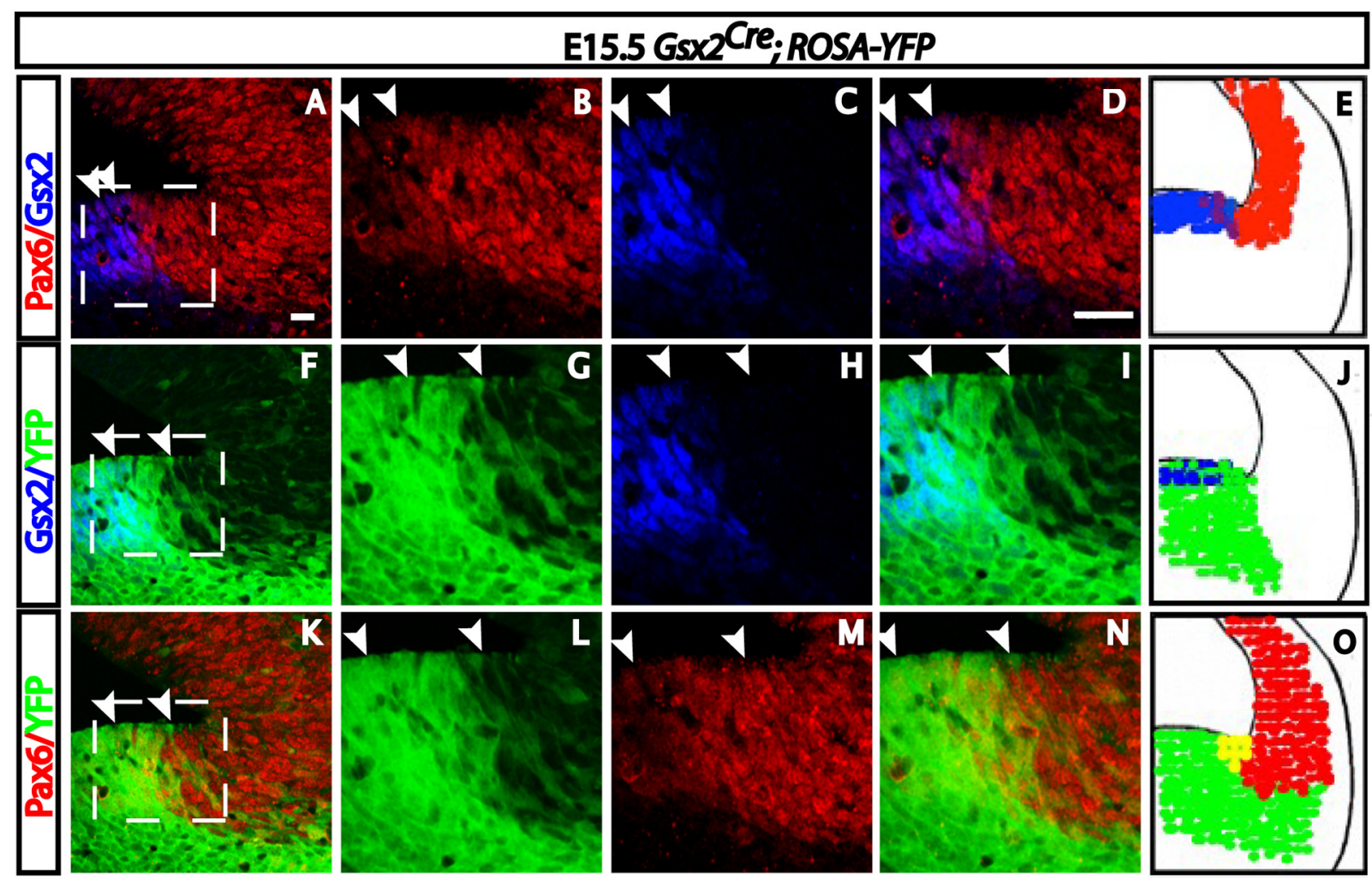

Figure 2. By E15.5, the PSB is largely refined into separate pallial and subpallial compartments. $A$, In the VZ of the PSB, Pax6 and Gsx2 protein overlap is reduced to only a few cell diameters. Arrowheads delineate the extent of Pax6-Gsx2 protein overlap. $\boldsymbol{B}$ - $\boldsymbol{D}$, Higher magnification of boxed area in $\boldsymbol{A}[\operatorname{Pax} 6(\boldsymbol{B}), G 5 \times 2(\boldsymbol{C})$, and overlay (D)] illustrates that there are very few cells coexpressing Pax6 and Gsx2 and no Pax6+/Gsx2 + cell mixing in the VZ. E, Schematic illustrating changes in Pax6 and Gsx2 expression at the PSB during development. F, YFP expression in the Gsx2-lineage embryo shows that Gsx2-lineage cells are present beyond the boundary of Gsx2 protein expression. Arrowheads delineate the boundary of Gsx2 and YFP protein expression. G-I, Higher magnification of boxed area in $\boldsymbol{F}[Y F P(G), G s \times 2(\boldsymbol{H})$, and overlay $(\boldsymbol{I})]$ shows the extended YFP + domain; arrowheads mark the edge of the Gsx2 and YFP protein domains.J, Schematicillustrates YFP expansion beyond Gsx2 expression. $\boldsymbol{K}$, Pax6 and YFP expression overlap at the PSB. Arrowheads mark the extent of overlap, which corresponds to the Gsx2 protein-negative domain and indicates that Gsx2-lineage cells, which are now Gsx2 protein-negative, have become Pax6+. $\boldsymbol{L}-\boldsymbol{N}$, Higher magnification of boxed area in $\boldsymbol{K}[$ YFP $(\boldsymbol{L})$, Pax6 $(\boldsymbol{M})$, and overlay $(\boldsymbol{N})]$ illustrates the YFP and Gsx2 overlapping domain at the PSB. Arrowheads mark the domain of Pax6+/NFP + overlap in the Gsx2 protein-negative PSB domain. 0, Schematic summarizing the pattern of refinement of Pax6-Gsx2 protein expression at the border between E11.5 and E15.5, and the formation of a Gsx2-lineage (YFP+) Gsx2 protein-negative, Pax6 protein-positive domain. Scale bars: $\boldsymbol{A}$ (for $\boldsymbol{A}, \boldsymbol{F}, \boldsymbol{K}), \boldsymbol{D}$ (for $\boldsymbol{B}-\boldsymbol{D}, \boldsymbol{G}-\boldsymbol{I}, \boldsymbol{L}-\boldsymbol{N}), 25 \mu \mathrm{m}$.

Pax6 (Fig. 1E, F). In contrast, by E15.5, gene expression at the PSB is largely refined, as the intermixing of these two progenitor domains is greatly reduced: fewer Gsx2 + cells are present in the Pax6+ domain and fewer Pax6+ cells are present in the Gsx2+ domain. In addition, with the exception of a few cell diameters of overlap at the border, Pax6 and Gsx2 protein coexpression in individual cells is also greatly reduced (Fig. $2 A, B$ ). We found that there was a significant difference between the widths of the domain of overlap of Gsx2+/Pax6 + cells at the PSB at E11.5, compared to E15.5 ( $p=0.0006$ ). Specifically, we found that the diameter of overlap of VZ cells expressing both Pax6 and Gsx2 was larger at E11.5, with an average width of 21.75 ( $S D=3.59$, $N=3$ ) cells, while at E15.5, the diameter of overlap of VZ cells expressing Pax6 and Gsx 2 was reduced to an average of 8.75 cells $(\mathrm{SD}=1.71, N=3)$. As YFP,$+ \mathrm{Gsx} 2-$, Pax6 + cells are present beyond the refined Gsx2+ domain at E15.5, this reveals that they have downregulated expression of Gsx 2 and upregulated expression of Pax6 (Fig. 2C-F,G). Thus, at least in the case of Gsx2+ dLGE progenitors, changes in gene expression are a mechanism that contributes to the refinement of the PSB.

We next wanted to determine whether the cell movements of progenitors across the PSB during development also contributed to refinement of the PSB. To accomplish this, we performed time-lapse imaging experiments using Pax6-GFP mice (Gong et al., 2003) to label the complementary dorsal side of the PSB (the vP), which is marked by high GFP expression, in comparison to the dLGE, which is marked by lower GFP expression (supplemental Figs. 1-3, available at www.jneurosci.org as supplemental material). Using two-photon microscopy to image E11.5 and E13.5 brain slices for at least $18 \mathrm{~h}$, we observed that cell movements across the PSB are much more frequent at E11.5, with numerous cells moving both dorsally and ventrally in the VZ and subventricular zone (SVZ). In contrast, at E13.5, cell movements are much less frequent and largely constricted to the SVZ (supplemental Figs. 1-3, available at www.jneurosci.org as supplemental material). These data indicate that as the border is refined and the number of overlapping cells decreases, both changes in transcription factor expression in cells locally at the PSB and a concomitant change in cell movement between the pallial and subpallial domains occur. Thus, our data suggest that both gene expression changes and cell movements contribute to refinement of the PSB.

\section{Fate of Gsx2-derived cells}

Cell transplantation and genetic fate-mapping studies (Stenman et al., 2003a; Carney et al., 2006; Waclaw et al., 2006, 2009, 2010; Brill et al., 2008; Hirata et al., 2009) have shown that cells derived from the PSB contribute to the amygdala and OB. We sought to determine the specific subtypes of neurons that dLGE Gsx2lineage progenitors gave rise to in these two structures. Specifically, we examined the distribution of YFP+ cells in Gs $x 2^{\text {Cre }}$; ROSA-YFP mice at P21. We found that in the lateral amygdala 


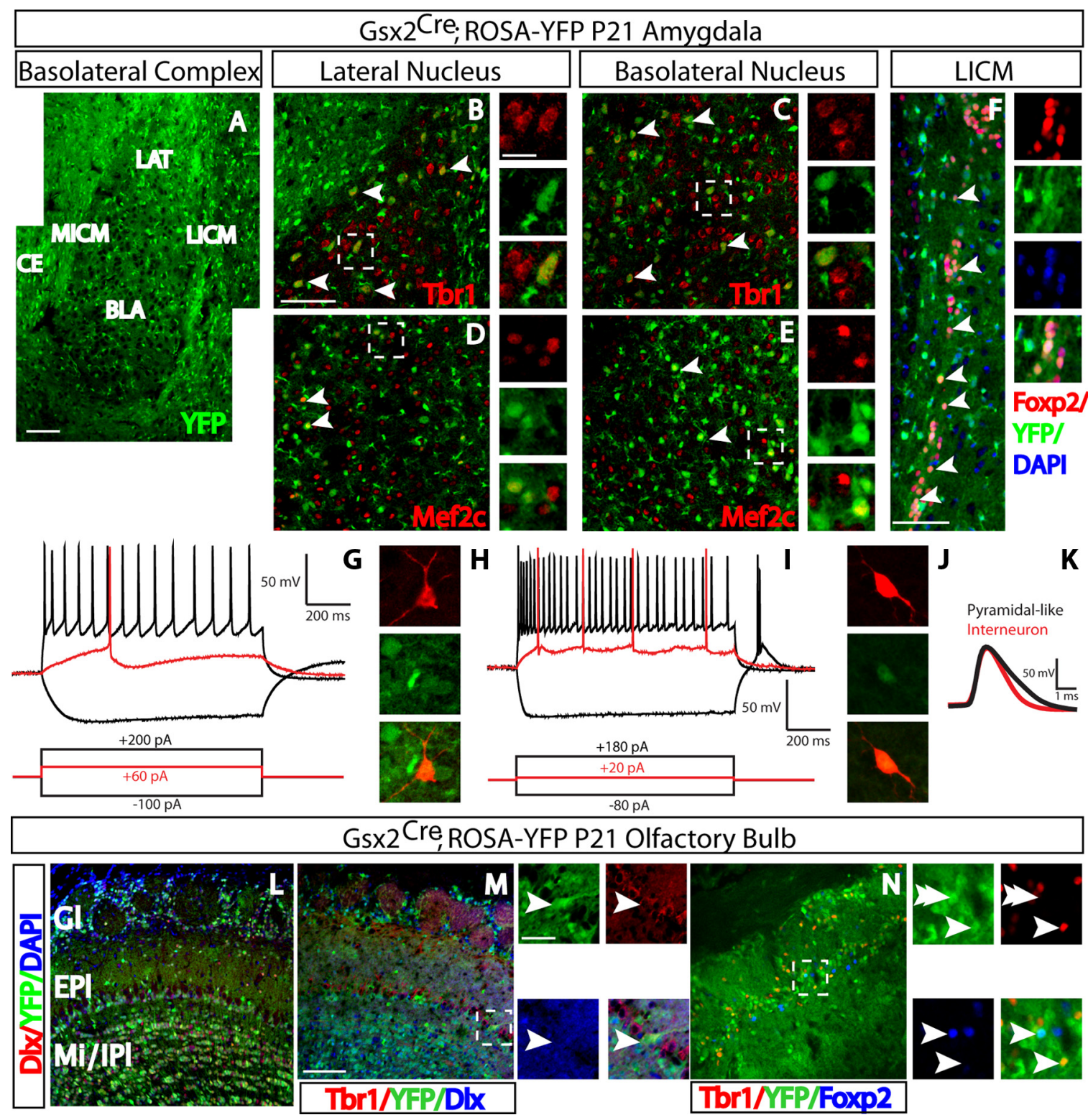

Figure 3. Multiple neuronal subtypes in the postnatal basolateral complex of the amygdala and olfactory bulb are derived from the Gsx2-lineage cells. $A$, Low-power magnification of the postnatal brain showing YFP + Gsx2-lineage cells throughout the BLC in P21 brains. B, C, Many YFP + cells coexpress the excitatory neuron marker Tbr1 in the LAT and BLA nuclei (arrowheads). Higher magnification of boxed areas in $\boldsymbol{B}$ and $\boldsymbol{C}$ highlights single-channel and overlay images. $\boldsymbol{D}, \boldsymbol{E}$, Mef2c, a transcription factor enriched in the LAT and implicated in neuronal differentiation, colabels with YFP cells in the LAT and BLA (arrowheads). Side panels show higher-magnification single-channel and overlay images of double-positive cells from boxed regions in $\boldsymbol{D}$ and $\boldsymbol{E}$. $\boldsymbol{F}$, GSX2-lineage YFP + /Foxp2 + inhibitory neurons are present in ICM, which is divided into the LICM and MICM (arrowheads point to cells in the LICM). Adjacent high-magnification images show single-channel and overlay of Foxp2 +/YFP + /DAPI + cells. G, Trace from recording of YFP + cell recorded in current clamp from fate-mapped Gsx2-lineage P21 brain slices from the LAT. Steps below the trace show corresponding current steps, at hyperpolarizing, rheobase, and maximum firing frequency levels. These cells exhibit a low maximum firing frequency and a large, slow AHP, characteristic of amygdala pyramidal excitatory neurons. $\boldsymbol{H}$, Post hoc immunohistochemistry of a biocytin-filled cell after recording (red) also expressing YFP (green) with characteristic pyramidal cell morphology. $I$, Trace of GFP + cell from the LAT that is representative of inhibitory interneurons recorded in these experiments, with a high maximum firing frequency and a small, biphasic AHP, characteristic of inhibitory interneurons. J, Post hoc immunohistochemistry of a biocytin-filled cell after recording (red) also expressing YFP (green) with bipolar cell morphology characteristic of inhibitory neurons. $\boldsymbol{K}$, Example of a single trace showing an action potential (AP) from a pyramidal-like neuron in $\boldsymbol{G}$ (black) and an interneuron in I(red); the pyramidal-like neuron AP is significantly broader than the interneuron AP. L, GsX2-lineage cells are present throughout the postnatal olfactory bulb; Dlx labels inhibitory cells throughout the OB and colabels with many YFP + cells. $M$, Higher magnification of the glomerular layer; arrowheads point to Dlx +/YFP + inhibitory neurons, which do not coexpress Tbr1. Tbr 1+, Gsx2-lineage cells do not coexpress Dlx; inset of $M$ highlights a YFP +/Tbr1+/Dlx - neuron. $\mathbf{N}$, YFP + cells in the glomeruli that colocalize with Tbr1 also do not coexpress Foxp2. Foxp2 labeling also marks inhibitory cells in the glomerular layer; single arrowheads point to YFP + cells that are also Foxp2+; double arrowheads point to YFP + cells that are also Tbr1 +. CE, Central nucleus; EPI, external plexiform layer; Gl, glomerular layer; IPI, internal plexiform layer; Ml, Mitral cell layer. Scale bars: $\boldsymbol{A}-\boldsymbol{F}, \boldsymbol{L}-\boldsymbol{N}, 100 \mu \mathrm{m}$; insets in $\boldsymbol{B}-\boldsymbol{F}, 25 \mu \mathrm{m} ; \boldsymbol{H}, \boldsymbol{J}$ (in $\boldsymbol{B}$, inset), $75 \mu \mathrm{m}$; insets in $\boldsymbol{M}$ and $\boldsymbol{N}, 50 \mu \mathrm{m}$.

(LAT) and basolateral amygdala (BLA), the majority of Gsx2lineage neurons expressed inhibitory markers such as calbindin (CB), calretinin (CR), parvalbumin (PV), and nitric oxide synthase (NOS) (supplemental Fig. 4, available at www.jneurosci.org as supplemental material). However, as revealed by expression of Tbr1, Gsx2-lineage cells also unexpectedly gave rise to a subpop- ulation of excitatory neurons (Fig. 3A-C). This represented 35\% $(257 / 740, N=3)$ of the total Tbr1 + population in the LAT and $11 \%(80 / 756, N=3)$ of the total Tbr1 + population in the BLA. In addition, Mef2c, which is enriched in the LAT nucleus of the amygdala (Waclaw et al., 2010), also marked a subpopulation of Gsx2-lineage cells $(22 \%, 186 / 835, N=3)$ (Fig. 3D,E). Gsx2- 
lineage cells also comprised the lateral ICM (LICM) and medial ICM (MICM) (Fig. 3F), a specialized group of amygdala inhibitory neurons likely derived from the PSB (Waclaw et al., 2010). The ICM plays a central role in modulating inhibitory input between the cerebral cortex, the basolateral complex, and the central nucleus, which together form an important circuit in mediating fear responses.

Previous studies have shown that LAT/BLA pyramidal-like excitatory neurons can be distinguished from interneurons based on their large soma and specific firing properties (Sah and Lopez De Armentia, 2003; Sah et al., 2003; Cocas et al., 2009). We therefore performed patch-clamp recordings of Gsx2-lineage cells with excitatory neuronal morphologies in P21 brain slices to examine whether they would exhibit pyramidal-like functional properties. These large, pyramidal-shaped Gsx2-lineage neurons had an average membrane capacitance of $120 \pm 44 \mathrm{pF}$ and an average membrane resistance of $278 \pm 89 \mathrm{M} \Omega(n=18)$ (supplemental Table 1, available at www.jneurosci.org as supplemental material). They all exhibited a regular but accommodating firing pattern (frequency $=16.8 \pm 3.8 \mathrm{~Hz}$; accommodation ratio $=$ $0.29 \pm 0.12 ; n=18)$ and a large and slow afterhyperpolarization (AHP) $\left(I_{\mathrm{AHP}}=-8.3 \pm 2.0 \mathrm{mV}\right.$; half-width AHP $=132 \pm 39 \mathrm{~ms}$; $n=18)$, both features typical of pyramidal-like neurons in the lateral amygdala (Fig. 3G,H; supplemental Table 1, available at www.jneurosci.org as supplemental material) (Sah et al., 2003; Cocas et al., 2009). These neurons could easily be distinguished from the few Gsx2-lineage interneurons that were also recorded $(n=3)$ (Fig. 3I-K). These interneurons exhibited a significantly lower membrane capacitance $\left(C_{\mathrm{m}}=40 \pm 21\right)$, higher membrane resistance $\left(R_{\mathrm{m}}=790 \pm 290 \mathrm{M} \Omega\right)$, higher firing frequency (frequency $=36 \pm 5 \mathrm{~Hz}$ ), biphasic AHP, and shorter action potential (half-spike duration $=1.5 \pm 0.3 \mathrm{~ms}$ ).

We also examined the fate of Gsx2-lineage cells in the P21 OB. Consistent with previous studies (Young et al., 2007), we found that this lineage gives rise to inhibitory neurons throughout the $\mathrm{OB}$, as indicated by colabeling with the inhibitory neuronal marker pan-Dlx and Foxp2 (Fig. 3L-N; see also Fig. 7). Interestingly, a small $(3 \%, 8 / 326, N=3)$ population of $G s \times 2$-lineage cells in the periglomerular layer also expressed the excitatory neuronal marker Tbr1 (Fig. $3 L-N$; see also Fig. $7 G$ ). The small population of Gsx2-lineage neurons that coexpressed Tbr1 did not express pan-Dlx, further indicative that these cells are likely to be excitatory neurons. Together these data demonstrate that within two limbic structures, the amygdala and the $\mathrm{OB}, G s \times 2$-lineage cells contribute to both excitatory and inhibitory neuronal populations.

\section{Effects of conditional Pax6 mutagenesis}

Our previous work (Corbin et al., 2003) and this study (Figs. 1, 2) reveal that during a distinct window of development a subpopulation of cells at the PSB express both Pax6 and Gsx2, and that Gsx2-lineage cells give rise to both excitatory and inhibitory neurons in the amygdala and OB (Fig. 3). Homozygous Small eye (Sey/Sey) Pax6 mutants exhibit disruption of the PSB, with expansion of subpallial cells into the pallial domain, a loss of pallialspecific gene expression, and abnormal cell migration (Stoykova et al., 1996; Mastick et al., 1997; Dellovade et al., 1998; Toresson et al., 2000; Jiménez et al., 2002; Stenman et al., 2003b; Talamillo et al., 2003; Kroll and O'Leary, 2005; Nomura et al., 2006; Carney et al., 2009). However, Sey/Sey mutants are embryonic lethal, which has confounded analysis of the postnatal consequences of Pax6 loss of function. To examine the consequences of PSB mispatterning on the generation of neuronal diversity in the postnatal brain, we sought to examine neuronal fate in Pax6 conditional mutants. To overcome embryonic lethality, we conditionally knocked out Pax6 in Gsx2-derived cells using Gs $x 2^{\text {Cre }}$; Pax $6^{\text {flox/flox }}$ mice.

We first examined putative embryonic patterning defects in Gs $x 2$-driven Pax6 conditional mutants (Gs $x 2^{\text {Cre }}$; Pax6 $6^{\text {flox/flox; }}$ ROSA-YFP mice- hereafter referred to as $P a x 6^{c K O}$ mice) compared to control $\left(\mathrm{Gs} \times 2^{\mathrm{Cre}}\right.$; $\left.\mathrm{Pax} 6^{+/+} ; \mathrm{ROSA}-\mathrm{YFP}\right)$ mice. Consistent with PSB changes previously observed in Sey/Sey mutants (Mastick et al., 1997; Yun et al., 2001; Carney et al., 2009), analysis at E12.5 and E15.5 revealed patterning defects specifically at the PSB. Expression of the vP secreted Wnt receptor Sfrp2 was substantially decreased in $\operatorname{Pax}^{c K O}$ mutants (Fig. $4 A, E$ ). The vPexpressed homeobox transcription factor $D b x 1$ was also severely reduced in $P a x 6^{C K O}$ embryos (Fig. $4 B, F$ ). In addition, expression of the dLGE marker $S p 8$ persisted and appeared slightly expanded (Fig. 4C,G). Expression of the pan-border marker and Ets family transcription factor Er81 appeared unaffected at the PSB (Fig. $4 \mathrm{D}, \mathrm{H})$. Additionally, expression of the dLGE and LCS Tea-shirt family transcription factor $T s h-1$ was preserved, indicating that the LCS amygdala migratory stream is not lost in $\operatorname{Pax}^{c K O} \mathrm{em}-$ bryos (Fig. $4 I, M$ ). These changes at the border were accompanied by a retraction of expression of pallial marker Ngn2 at the PSB; however, its expression in the remainder of the pallium was normal (Figs. $4 J, N, 5 F, L$ ). Further, the expression pattern of the subpallial marker Islt1, which marks the developing striatum, was unaffected, indicating that the patterning defects in these mutants do not extend into the LGE (Fig. $4 K, O$ ). Finally, an examination of the VZ/SVZ-expressed LGE patterning homeobox transcription factor $D l x 1 / 2$ revealed the presence of $D l x 1 / 2+$ cortical heterotopias in $\mathrm{Pax}_{6} 6^{\mathrm{KOO}}$ embryos, a finding reminiscent of cortical malformations in Sey/Sey mutants. Moreover, LCS expression persists and may be expanded (Fig. $4 L, P$ ), similar to Tsh 1 expression (Fig. 4I,M). Collectively, these data reveal local PSB patterning defects characterized by a decrease in vP markers (Sfrp2, Dbx1) and a persistence/possible expansion of dLGE/LCS markers (Tsh1, Dlx1/2).

We next analyzed whether $\operatorname{Pax}_{6} 6^{\mathrm{KO} O}$ embryos displayed an alteration of pallial and subpallial marker expression locally at the PSB. In E15.5 Pax $6^{c K O}$ embryos, Pax6 expression was decreased at the PSB and vP compared to controls (Fig. 5A, B, G,H). Coordinated with this, Pax6 expression was also decreased in $P a x 6^{c K O}$ embryos in the developing amygdala (Fig. 5C,I). In contrast, the Gsx2-lineage (YFP+) domain was expanded, encroaching closer to the sulcus (Fig. 5D, J). In addition, the domain of Gsx2 expression was expanded, with more Gsx2+ cells scattered ectopically in the $\mathrm{vP}$ (Fig. $5 E, K$ ). Expression of $\mathrm{Ngn} 2$ was also decreased at the vP in E13.5 Pax $^{c K O}$ mutants, further indicating that the $\mathrm{vP}$ domain was abnormal in these embryos (Fig. $5 F, L$ ). Collectively, these results indicate that, rather than the global patterning defects previously observed in Sey/Sey mutants, $\mathrm{Pax}^{c K O}$ embryos have focal patterning defects that are largely restricted to the PSB, characterized by a decrease of the $\mathrm{vP}$ domain and an expansion of the dLGE domain.

We next sought to examine the long-term consequences of PSB disruption on neuronal diversity in two regions known to be derived from the PSB: the amygdala and the OB. In the amygdala, we found that the overall structure of the BLC appeared normal (Fig. 6A,D). We also examined the number and distribution of inhibitory interneurons in the BLC, and quantified the number of $\mathrm{CB}+, \mathrm{CR}+, \mathrm{NOS}+$, and $\mathrm{PV}+$ inhibitory interneuron subpopulations in the LAT and BLA. We found that while the numbers of $\mathrm{CR}+, \mathrm{NOS}+$ and $\mathrm{PV}+$ inhibitory neuron subpopulations were not significantly changed in the $\operatorname{Pax}_{6} 6^{\mathrm{KOO}} \mathrm{BLC}$, there was a 


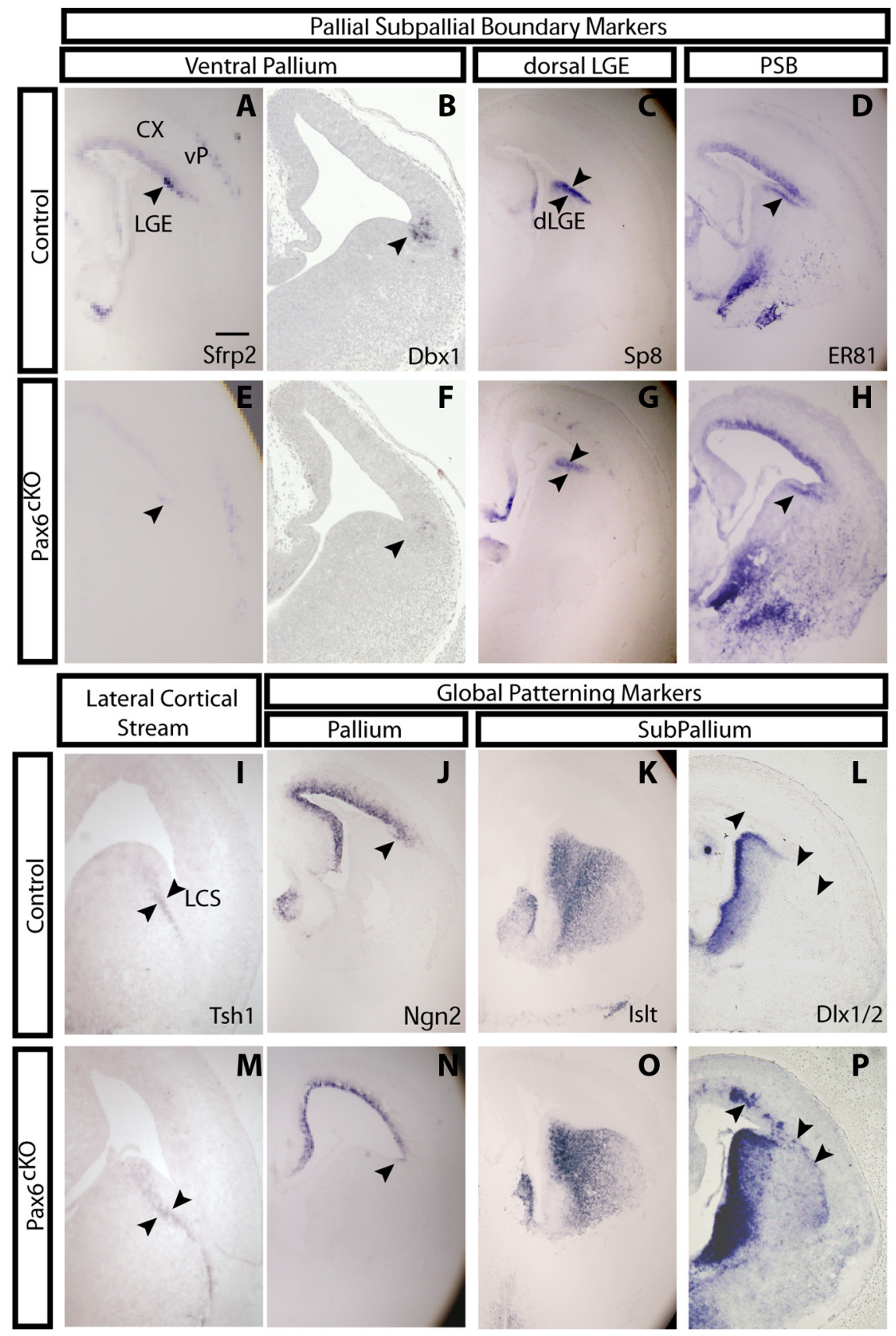

Figure 4. Embryonic PSB-specific patterning defects in Pax ${ }^{c K O}$ embryos. In situ hybridization analysis is shown at E12.5 $(\boldsymbol{B}, \boldsymbol{F})$ and E15.5 (all other panels). $\boldsymbol{A}$, Expression of Sfrp2 marks the VP as shown in control (arrowhead). $\boldsymbol{E}, \operatorname{In}$ Pax ${ }^{\mathrm{CKO}}$ embryos, Sfrp2 expression is severely reduced (arrowhead). $\boldsymbol{B}$, The homeobox transcription factor $D b x 1$ is expressed at the vP in control embryos. $\boldsymbol{F}, \operatorname{In} P a \times 6^{C K O}$ embryos, Dbx 1 expression is severely reduced at the PSB. C, Sp8 marks the dLGE. G, In Pax ${ }^{C K O}{ }^{\mathrm{C} O}$, Sp 8 persists and appears expanded. Arrowheads show domain of Sp8 expression. D, ER-81 expression marks both the VP and dLGE in control embryos. $\boldsymbol{H}$, In Pax $6^{C K O}$ embryos, ER-81 expression boundaries are less refined. $I$, Tsh- 1 marks the dLGE as well as the LCS in control embryos. $\boldsymbol{M}$, Tsh 1 remains expressed in $\mathrm{Pax}^{6}{ }^{\mathrm{CKO} O}$ embryos, indicating that the LCS is not lost in these mutants. Arrowheads point to Tsh-1+ LCS. $\boldsymbol{J}, \mathrm{Ngn} 2$ is expressed throughout the pallium VZ in control embryos. $N$, In Pax $6^{\mathrm{CKO}}$ embryos, Ngn2 expression is decreased at the vP but not lost in the pallium. $\boldsymbol{K}$, The subpallial-expressed transcription factor IsIt 7 labels the differentiating zone of the LGE in control embryos. $\mathbf{0}$, Islt 1 expression is not affected in Pax ${ }^{c K O}$ embryos. $\boldsymbol{L}$, The homeobox transcription factor D/x $1 / 2$ is expressed throughout the $L G E$ in control embryos. $P, \operatorname{In} P a x 6^{c K 0}$ embryos, D/x1/2 is expanded dorsally and laterally into the vP and along the LCS. Scale bar: $A, C-E, G-P, 250 \mu \mathrm{m} ; \boldsymbol{B}, \boldsymbol{F}, 300 \mu \mathrm{m}$.

small, but significant, increase in the number of $\mathrm{CB}+$ inhibitory interneurons in the LAT, but not BLA (supplemental Fig. 4, available at www.jneurosci.org as supplemental material). This suggests a possible fate change from LAT excitatory/ICM neurons to $\mathrm{CB}+$ inhibitory neurons. In contrast, there was a significant de- crease in the numbers of Foxp2+ lateral and medial ICM neurons (Fig. $6 A, B, E, F, I)$. Additionally, the number of Gsx2-lineage Tbr1+ excitatory neurons was significantly decreased in $\operatorname{PaxG}^{c K O}$ mice in the LAT (Fig. 6A, $C, E, G, I$ ). Interestingly, however, there were no significant decreases in the number of Gsx2-lineage Tbr1+ neurons in the BLA (Fig. 6A, D, E, H,I). We next wanted to examine whether Mef2c+ neurons, which likely overlap with Tbr1 to label excitatory neurons in the LAT (Waclaw et al., 2010), were also reduced in $\mathrm{Pax} 6^{c K O}$ mice. Similar to Tbr1+ neurons, we found that the total number of Mef2c+ neurons in the LAT was decreased in $\operatorname{Pax}^{c K O}$ mice (data not shown). Analogous to the Tbr1+ population, this difference was not significant when compared to the total numbers of cells (742/1289, Mef2c+/DAPI+, $N=3$ control; vs 763/1154, Mef2c+/ DAPI,$\left.+ N=3 \operatorname{Pax}^{c K O}\right)$. However, when comparing the numbers of Mef2c+Gsx2lineage neurons in the LAT and BLA of $\operatorname{Pax6}^{\mathrm{cKO}}$ mice (data not shown), we found that the numbers of Gsx2-lineage Mef2c+ neurons in the LAT were also significantly decreased $(p=0.0418)$ in Pax $6^{c K O}$ mice (36\%, 192/537 Mef2c+/Gsx2-lineage cells in control compared to $18 \%, 81 / 447$ Mef2c+/Gsx2-lineage; $N=3$ control and $\left.\operatorname{Pax}^{6 K O}\right)$. We also found that Mef2C+1 Gsx2-lineage neurons were not significantly decreased in the BLA (data not shown). These data indicate that in LAT nucleus of the BLC, Pax6 is required in the Gsx2-lineage for the generation of a subpopulation of excitatory neurons, as well as inhibitory $\mathrm{CB}+$ interneurons and ICM neurons.

Next, we examined the consequences of the conditional loss of Pax6 on the generation of neuronal diversity in the postnatal OB. Previous work has shown postnatal OB interneuron defects in Sey heterozygotes, but analysis of Sey homozygotes has not been possible due to embryonic lethality (Dellovade et al., 1998; Kohwi et al., 2005; Nomura et al., 2007; Brill et al., 2008; Haba et al., 2009). Despite the fact that many OB cells are derived from the Gsx2-lineage, the general structure of the $\mathrm{OB}$ appeared normal in P21 Pax6 ${ }^{c K O}$ mutants (Fig. 7). However, the total percentage of Gsx2-lineage cells in the glomerular layer was decreased in $\mathrm{Pax}^{{ }^{C K O}}$ mice (44\%, in control mice compared to $37 \%$, in $P a x 6^{c K O}$ mice, $p=0.03, N=3$ ). When we examined interneuron subtypes, we found significant decreases in the numbers of $\mathrm{TH}+, \mathrm{PV}+$, and $\mathrm{CR}+$ interneuron subtypes (Fig. $7 C-F, I, J)$. In contrast, there were no significant differences in $\mathrm{CB}+$ interneurons or Tbrl+ excitatory neurons (Fig. 
$7 A, B, G-I)$. These data reveal that Pax6 functions in Gsx2+ cells to generate the correct numbers and types of interneurons in the $\mathrm{OB}$

In summary, the results presented here reveal that the pallial-subpallial boundary is a dynamic border, with a decrease in the number of cells coexpressing Pax6 and Gsx2 and a decrease in the intermixing of Pax6 + and Gsx2+ cells in their respective pallial and subpallial domains during development. Our Gsx2-fate-mapping data and time-lapse imaging experiments suggest that this PSB refinement occurs via changes in gene expression (Figs. 1,2) and complementary changes in cell motility, with fewer cell movements occurring in the VZ of the PSB as development proceeds (supplemental Figs. 1-3, available at www.jneurosci.org as supplemental material). Using genetic fate mapping to label the Gsx2+ dLGE, we found that cells from this domain gave rise to both excitatory and inhibitory lineages in the amygdala and $\mathrm{OB}$ (Fig. 3). The conditional ablation of Pax6 from cells that also express Gs $x 2$ resulted in abnormal patterning at the $\mathrm{PSB}$, specifically, reduction of the $\mathrm{vP}$ and an ectopic expansion of the dLGE (Figs. 4, 5 ). This PSB disruption resulted in differential alterations in neuronal cell subpopulations in the amygdala and $\mathrm{OB}$, regions that are seeded by cells from the PSB. Specifically, the numbers of inhibitory interneurons (but not excitatory neurons) were decreased in the $\mathrm{OB}$ and the numbers of excitatory neurons and ICM interneurons were decreased in the LAT nucleus of the amygdala, while the numbers of $\mathrm{CB}+$ inhibitory interneurons were increased in this same structure (Figs. 6, 7; supplemental Fig. 4, available at www. jneurosci.org as supplemental material). These findings provide an important link between the essential function of Pax6 during the development and patterning of the embryonic brain and the generation of neurons that give rise to the postnatal limbic system.

\section{Discussion}

While the establishment of other borders within the nervous system, for example, the mid-hindbrain boundary, has been extensively explored, development of the telencephalic PSB remains less well understood. Our current and previous work (Corbin et al., 2003) demonstrates that PSB establishment is highly dynamic, characterized by significant changes in gene expression during neurogenesis. In addition, previous studies from our laboratory and others have shown that PSB-derived cells contribute extensively to the limbic system, most prominently to the amygdala and the OB (Stenman et al., 2003a; Carney et al., 2006; Lledo et al., 2008; Hirata et al., 2009; Waclaw et al.,

\section{Embryonic Control}
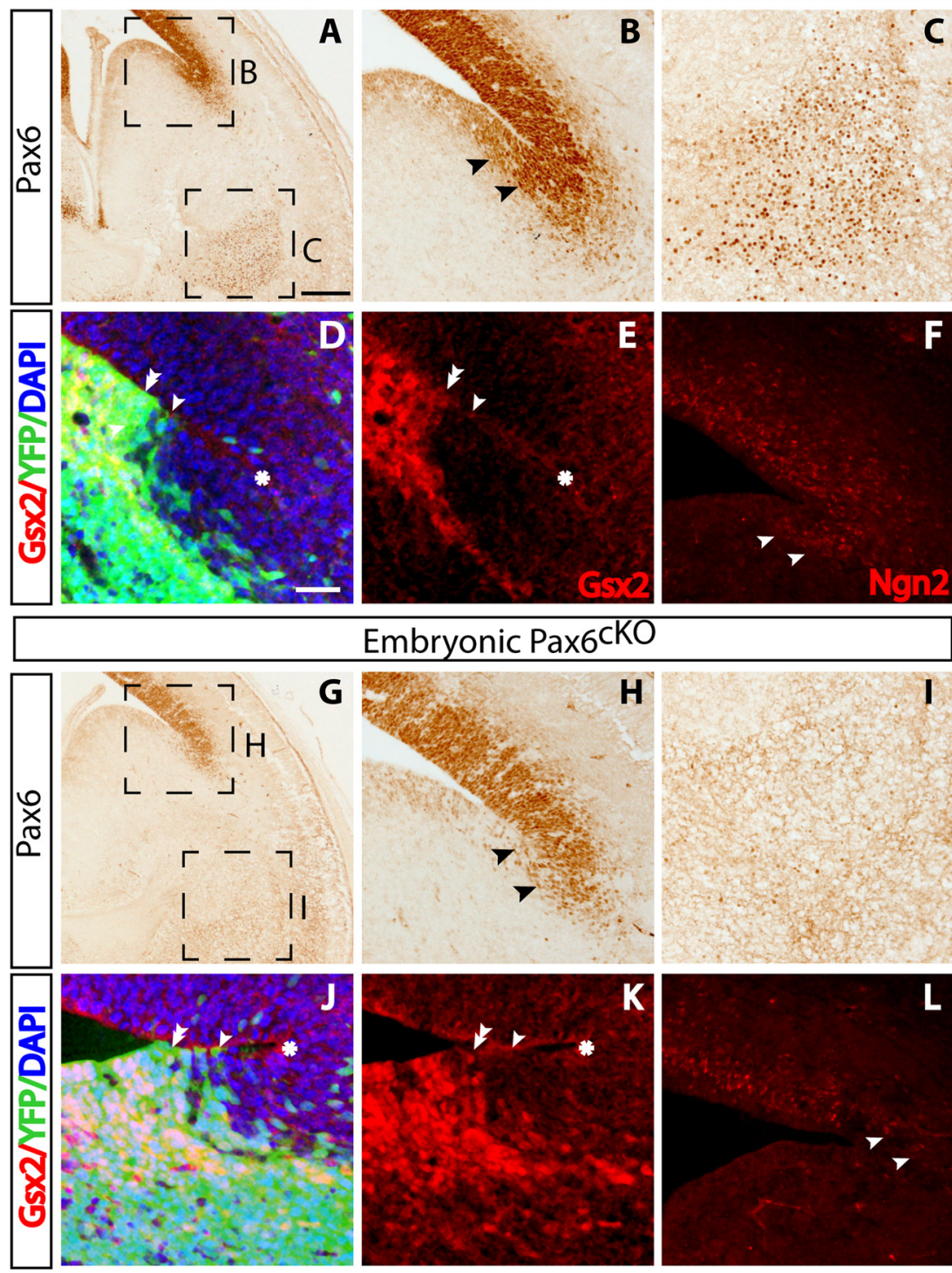

Figure 5. The PSB in Pax6 ${ }^{C K O}$ mutants is expanded dorsally during embryogenesis. $A$, Pax6 is expressed in the pallium and $v P$ in E15.5 control embryos. $\boldsymbol{B}$, Higher magnification of PSB from $\boldsymbol{A}$ showing high expression of Pax6 in the VZ (arrowheads). $\boldsymbol{C}$, Higher magnification of amygdala primordium from $\boldsymbol{A}$, with numerous Pax6 + cells. $\boldsymbol{D}, \mathrm{In}$ E15.5 control embryos, the GsX2-lineage YFP + cell domain (arrowhead) extends beyond the Gsx2 protein domain (double arrowhead); asterisk marks the sulcus. $\boldsymbol{E}$, Single channel of Gsx2 protein expression is also shown; asterisk marks the sulcus; arrowheads are as in $\boldsymbol{D}$. F, Ngn2 expression in Pax6 ${ }^{c K O}$ control $^{c}$ brain at E13.5; Ngn2 expression is present throughout the pallium and stops at the VP. G, In E15.5 Pax6 $6^{\text {CKO }}$ mice, Pax6 expression is decreased in the vP (arrowheads). $\boldsymbol{H}$, Higher magnification of PSB of $\mathbf{G}$ illustrates that there are fewer Pax6+ cells in the vP. $\boldsymbol{I}, \mathbf{I n}$ the Pax6 ${ }^{C K O}$ amygdala primordium, few cells are labeled with Pax6. J, In E15.5 Pax6 ${ }^{C K O}$ embryos, the Gsx2 protein domain and Gsx2-lineage domain is ectopically expanded dorsally toward the sulcus (as evidenced by the decrease in distance between the arrowheads and the asterisk). $\boldsymbol{K}, \mathrm{Gsx2}$ protein expression alone; Gsx2 + cells are ectopically dorsally expanded toward the sulcus. $\boldsymbol{L}$, In E13.5 Pax6 ${ }^{C K O}$ embryos, Ngn2 expression is decreased at the PSB, with fewer Ngn2 + cells in the vP. Scale bars: (in $\left.\boldsymbol{A}\right) \boldsymbol{A}, \boldsymbol{G}, 250$ $\mu \mathrm{m}$; (in D) $\boldsymbol{B}-\boldsymbol{F}, \boldsymbol{H}-\boldsymbol{L}, 100 \mu \mathrm{m}$.

2009). In this study, we found that the refinement of the PSB, as defined by separation of the majority of high Pax6 + and Gsx2+ progenitors, is generally complete by midneurogenesis (E15.5). We also reveal that a major mechanism of PSB refinement is via changes in gene expression, as many Gsx $2+$ cells change their fate to express Pax6. We further find that the permeability of the border, as evidenced by cell movements in the ventricular zone, decreases with development. Thus, refinement of the PSB is driven by both changes in gene expression in individual cells and by changes in the fluidity of cell 




Figure 6. Alterations of Gsx2-derived excitatory and inhibitory cell subpopulations in the Pax6 ${ }^{\mathrm{CKO}}$ postnatal amygdala. $\boldsymbol{A}-\boldsymbol{E}_{\text {, }}$ Low-power magnification of the BLC, illustrating numerous of Gsx2-lineage cells and localization of Tbr1 + excitatory neurons and Foxp2 + ICM inhibitory neurons in control $(\boldsymbol{A})$ and $\operatorname{Pax6}^{C K O}(\boldsymbol{E})$ mice at P21. $\boldsymbol{B}$, Higher magnification of boxed LICM region in $\boldsymbol{A}$ reveals Gsx2-lineage neurons (YFP+) coexpressing Foxp2 (arrowheads) but not Tbr1 in control mice. $\boldsymbol{F}$, Higher magnification of boxed region in $\boldsymbol{E}$ shows that fewer cells coexpress Foxp2 and YFP in the LICM region in Pax ${ }^{C K O}$ brains (arrowheads mark YFP + I Foxp2 + cells). C, G, Higher magnification of boxed region of the LAT nucleus from $\boldsymbol{A}$ and $\boldsymbol{E}$ is shown. Tbr1 + /Gsx2-lineage cells in the LAT nucleus are numerous in control $(\boldsymbol{C})$ and greatly decreased in $\operatorname{Pax}^{\mathrm{CKO}}$ mutants $(\boldsymbol{G})$; arrowheads point to $\mathrm{Tbr} 1+/ \mathrm{YFP}+$ cells. Boxed regions in Cand $\mathbf{G}$ are magnified in right panels: YFP (green), Tbr 1 (red), DAPI (blue), and overlay. $\boldsymbol{D}, \boldsymbol{H}$, Higher magnification of the BLA region shows less Tbr1 + Gsx2-lineage in the LAT nucleus, in both control $(\boldsymbol{C})$ and $\operatorname{Pax}^{\mathrm{CKO}}(\boldsymbol{G})$ brains. Arrowheads mark double + cells. Boxed regions in $\boldsymbol{D}$ and $\boldsymbol{H}$ are magnified in right panels: YFP (green), Tbr1 (red), DAPI (blue), and overlay. $\boldsymbol{I}$, Quantification of cell counts in control and Pax6 ${ }^{c K O}$ amygdalae, in the LAT, BLA, and LICM subregions. In the LAT nucleus, $45 \%$ of DAPI+ cells expressed Tbr1 in control mice $(740 / 1642, N=3)$ versus $39 \%$ in Pax $6^{6 K O}$ mice $(594 / 1510, N=3 p=0.08)$. The number of Gsx2-lineage Tbr1 + cells (double + ) in the LAT nucleus was significantly decreased from $16 \%$ in control mice (257/ $1642, N=3)$ to $3 \%(55 / 1769, N=3)$ in Pax $6^{c K O}$ mice $(p=0.002)$. In the BLA nucleus, Tbr1 + cell numbers or YFP $+/$ Tbr1 + cells were not significantly different in Pax6 ${ }^{C K O}$ mice; $5 \%(80 / 1643, N=3)$ of control Gsx2-lineage cells and $3 \%(45 / 1450, N=3)$ of Pax6 $^{G K O}$ Gsx2-lineage cells were double positive ( $\left.p=0.92\right)$. In the LICM, 68\% (158/232, $\left.N=4\right)$ of Gsx2-lineage cells were Foxp2 + in control mice, versus $57 \%(136 / 237, N=4)$ in Pax $6^{c K O}$ mice, a significant decrease $(p=0.02)$; in the medial ICM, in control mice, $52 \%$ of Gsx2-lineage cells were Tbr1 $+(173 / 335, N=4)$, whereas in Pax $^{c K O}{ }^{c K}$ mice, $41 \%$ were double positive for Tbr1 and YFP $(115 / 280 ; N=4)$, also a significant decrease $(p=0.02) .{ }^{*} p<0.05 ;{ }^{* *} p<0.01$. Scale bars, $100 \mu \mathrm{m}$.

movements at the PSB. These developmental mechanisms for refining the boundary are likely used to prevent pallial and subpallial compartments from mixing with each other later in development, and may occur via differential cell adhesion molecule expression (Stoykova et al., 1997; Nomura et al., 2006).

Although our findings show that the PSB is largely refined by E15.5, the question arose as to what role, if any, Pax6 plays in
Gsx2 + cells at the PSB. To directly address this, we knocked out Pax6 only in cells that coexpress Gsx2. During embryogenesis, we observe an expansion of the dLGE at the expense of the $\mathrm{vP}$, consistent with patterning defects observed in full Pax6 (Sey/Sey) mutants (Stoykova et al., 1996; Yun et al., 2001; Stenman et al., 2003b; Talamillo et al., 2003; Carney et al., 2009). As the PSB is the origin of cells that will populate the amygdala and $\mathrm{OB}$, the well characterized patterning defects in Sey/ Sey mutants are predictive of limbic system disruptions. Consistent with this, we find that Pax6 is necessary in Gs $x 2+$ cells for the correct formation of specific excitatory and inhibitory neuron populations in the postnatal amygdala as well as subsets of interneurons in the OB.

Previous gene expression and fatemapping studies have revealed that the amygdala is derived from multiple progenitor pools, including the PSB (Nery et al., 2002; Tole et al., 2005; Carney et al., 2006; Cocas et al., 2009; Hirata et al., 2009; Waclaw et al., 2010). The vP and dLGE components of the PSB generate subpopulations of excitatory and inhibitory neurons that largely populate the amygdala BLC. Earlier work from our laboratory and others has shown that both pallial- and subpallial-derived progenitor pools, as well as diencephalic sources, contribute to neuronal diversity the amygdala (Cocas et al., 2009; Hirata et al., 2009; GarcíaMoreno et al., 2010; Waclaw et al., 2010). With regard to the BLC, our previous genetic fate-mapping studies have revealed that dorsal pallial-derived $E m \times 1+$ and vP-derived $D b x 1+$ populations generate excitatory neurons (Cocas et al., 2009; Hirata et al., 2009). In contrast, it appears that the Gsx2+ dLGE may be a major source of the specialized ICMs (Waclaw et al., 2010).

It is of interest to note that while the generation of inhibitory neurons from the Gsx2 lineage is consistent with the subpallial expression of this gene, our finding that Gsx2-lineage neurons also generate a significant population of excitatory neurons was surprising. The most straightforward interpretation is that this population is derived from the transient PSB Gs $\times 2+/$ Pax6 + progenitor pool. Thus, a broader picture is emerging in which amygdala excitatory neurons are generated from sets of genetically identifiable pallial-derived progenitor pools. Indeed, the broad reduction (but not complete loss) of $D b x 1$ expression in the $\mathrm{vP}$ in Pax6 conditional mutants indicates that Gsx2-lineage amygdala excitatory neurons may be a subset of $D b x 1$-lineage excitatory neurons. However, the full extent of overlap between Emx1+, $D b x 1+P a x 6+$, and Gs $x 2+$ progenitors and how these genes act 


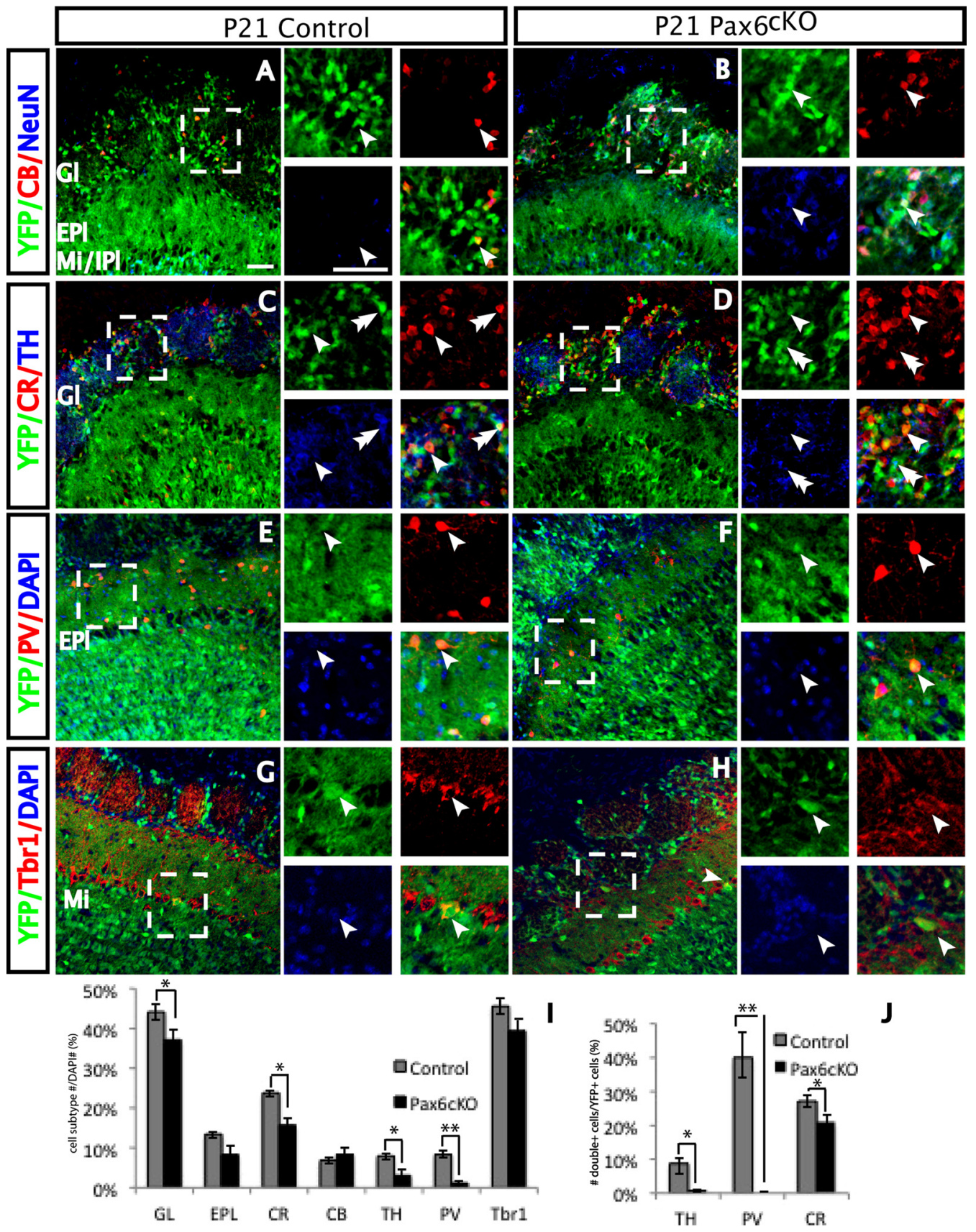

Figure 7. Inhibitory but not excitatory cell subpopulations are altered in the Pax ${ }^{c K O}$ postnatal olfactory bulb. $A, B, C B$ and NeuN mark inhibitory neurons in the glomerular layer, which colocalize with YFP expression. № change in $C B+$ cells was observed between control and $P a \times 6^{C K O}$ mice. Panels to the right are from boxed regions in $A$ and $B$ : YFP (green), $C B$ (red), NeuN (blue), and overlay (arrowheads mark $\left(B+/ Y F P+\right.$ cells). $C, D, C R+$ and TH+ interneurons also colocalize with YFP in the glomerular layer. Both interneuron markers are reduced in Pax ${ }^{c k 0}$ glomeruli. Panels to the right are from boxed regions in Cand $\boldsymbol{D}$ : YFP (green), CR (red), TH (blue), and overlay (arrowheads mark CR + YFP + cells, double arrowheads mark TH $+/$ YFP + cells). $\boldsymbol{E}, \boldsymbol{F}$, PV + cells in the EPL coexpress YFP in control mice. In the Pax6 ${ }^{\text {GKO }}$ $\mathrm{OB}$, these numbers are greatly reduced. Panels to the right are from boxed regions in $\boldsymbol{E}$ and $\boldsymbol{F}$ : YFP (green), PV (red), DAPI (blue), and overlay (arrowheads mark PV +/YFP + cells). G, $\boldsymbol{H}, \mathrm{Tbr} 1+$ cells in the PGL and EPL rarely coexpress YFP. There is no change in these Gsx2-lineage Tbr1 + cell in the Pax $6^{\mathrm{CKO}}$ mutant $0 B$.I, Graph of the total number of inhibitory interneuron subtypes in control and Pax ${ }^{6 \mathrm{KO} O}$ mice, compared to the total number of DAPI+ cells. J, Quantification of the number of Gsx2-lineage $\mathrm{TH}+, \mathrm{PV}+$, and $\mathrm{CR}+$ interneurons in control and Pax6 $6^{\mathrm{CKO}}$ mutant $0 \mathrm{~B}$. The numbers of these three cell subtypes were significantly decreased in mutants, while (B + and Tbr1 + numbers were not affected. These changes were observed in both their total (DAPI-colabeled) numbers and the number of Gsx2-lineage (YFP + ) cell populations. Changes in the total numbers were as follows: TH: $6 \%(85 / 1546, N=3)$ in control mice versus $2 \%(32 / 1843, N=3)$ in Pax ${ }^{c K O}$ mice $(p=0.04)$; PV: $10 \%(60 / 624, N=3)$ in control mice, $1 \%$ $(10 / 877, N=3)$ in Pax $6^{c K O}$ mice $(p=0.002) ; C R: 23 \%(360 / 1546, N=3)$ in control mice versus $15 \%(284 / 1843, N=3)$ in Pax6 ${ }^{c K O}$ mice $(p=0.03)$. Changes in each marker in Gsx2-lineage numbers are as follows: the number of $\mathrm{CB}+$ Gsx2-lineage interneurons was not changed $\left[10 \%(98 / 992, N=3)\right.$ in control, $13 \%(102 / 806, N=3)$ in Pax ${ }^{c K 0}$ mice $\left.(p=0.06)\right]$, but TH,+ PV + , and $C R+G 5 x 2$-lineage interneurons were decreased: TH: $9 \%(63 / 718, N=3)$ in control mice versus $1 \%(7 / 652, N=3)$ in Pax6 ${ }^{6 K O}$ mice $(p=0.01) ; P V: 43 \%(34 / 80, N=3)$ in control mice versus $0 \%(0 / 71, N=3)$ in Pax6 $6^{C K O}$ mice $(p=0.008) ; C R: 27 \%(192 / 718, N=3)$ in control mice versus $21 \%(135 / 652, N=3)(p=0.04)$. The number of Tbr1 + excitatory neurons in the periglomerular layers was not altered in Pax ${ }^{c K 0}$ mice: $25 \%$ $(200 / 802, N=3)$ of DAPI+ cells were Tbr1 + in control mice versus $30 \%(233 / 780, N=3)$ of Tbr1 + cells in Pax $6^{c K O}$ mice $(p=0.053) .{ }^{*} p<0.05 ;{ }^{* *} p<0.01$. Scale bars, $50 \mu \mathrm{m}$.

in concert to specify different functional excitatory neuronal subtypes in a combinatorial manner remains to be fully elucidated.

Regardless of how these genes act in combination to specify putative amygdala excitatory neuronal diversity, our Pax6 condi- tional mutagenesis data provide important and novel insight into the function of Pax6 in amygdala formation. The loss of Pax6 specifically in Gsx2+ cells results in a significant decrease in the number of BLC Gsx2-derived excitatory neurons. Interestingly, 
this effect is only observed in the LAT and not the BLA, revealing that Pax6 expression in Gsx2-expressing progenitors is differentially required for generation of neuronal diversity in these two amygdala subdomains. Complementing our findings is the previous analysis of conditional Gsx2 mutants, which display the opposite result - an increase in excitatory neurons in the amygdala, also specifically in the lateral and not the basolateral nucleus (Waclaw et al., 2010). Together, these results reveal that there is an absolute requirement for Pax6, but not Gsx2, in Gsx2expressing progenitors, in the generation of LAT, but not BLA, amygdala excitatory neurons.

Also interesting is the effect of the conditional loss of Pax6 on the generation of neurons in the ICMs. These neurons regulate feedforward inhibition and are an essential component of fear circuitry. Recent studies have revealed that Gsx2 and Sp8 are required for the specification of these neurons (Waclaw et al., 2009, 2010). As we reveal that the conditional loss of Pax6 results in an expansion of Gsx2 at the PSB during embryogenesis, we would predict a complementary finding: an increase in ICM numbers. In contrast to this prediction, we find that the conditional loss of Pax6 in Gs $x 2+$ cells results in a significant decrease in cells in the ICM. Therefore, it appears that Pax6 expression in $G s \times 2+$ cells is also indispensable for the correct specification of ICM cells. However, in contrast to specification of LAT excitatory neurons, which can be specified in the absence of Gsx2, both Pax6 and $G s \times 2$ are required for ICM generation.

In the $\mathrm{OB}$, our Pax 6 conditional mutants show a loss of $\mathrm{CR}+$, $\mathrm{TH}+$, and $\mathrm{PV}+$ subclasses of interneurons. The decrease in $\mathrm{TH}+$ and $\mathrm{PV}+$ populations is consistent with previous studies of Pax6 function (Dellovade et al., 1998; Kohwi et al., 2005; Brill et al., 2008; Haba et al., 2009). Thus, the decrease in TH+ and PV+ interneurons in Pax6 conditional mutants is due to a direct loss of function of Pax6 in populations that express Gs 2 . In contrast, the decrease in $\mathrm{CR}+$ neurons, similar to changes in amygdala ICM neurons, is not predicted by previous analyses. Previous studies have shown that specification of $\mathrm{CR}+$ neurons requires normal function of the zinc finger gene, Sp8 (Waclaw et al., 2006, 2009). Moreover, $S p 8$ is regulated by Gsx2, as $S p 8$ expression is lacking in Gsx2 mutants (Waclaw et al., 2009). However, our conditional Pax6 mutants display a maintained expression of Sp8 and expanded Gsx2 expression at the PSB. Thus, since disruption of either Gsx2 or Pax6 results in CR+ interneuron loss in the OB, it appears that similar to specification of ICM amygdala neurons, both Pax6 and Gs 2 are required to specify the OB CR+ population, and may work in concert. Such a result is reminiscent of the combinatorial role of Pax 6 and Dlx in the postnatal generation of dopaminergic $(\mathrm{TH}+)$ periglomerular neurons in the $\mathrm{OB}$ (Brill et al., 2008). While we cannot rule out the possibility that some adult-born cells in the SVZ express Pax6 and Gsx2, and are therefore also affected in our $\mathrm{Pax} 6^{c K O}$ mice, $\mathrm{TH}+, \mathrm{PV}+$, and $\mathrm{CB}+\mathrm{OB}$ interneuron generation peaks during embryogenesis (BatistaBrito et al., 2008) at the time that Pax6 and Gsx2 are overlapping at the PSB. Collectivity, these studies suggest a model in which Pax6 and Gs $x 2$ are differentially required for the specification of unique subpopulations of $\mathrm{OB}$ inhibitory neurons and of excitatory neurons and specialized ICM inhibitory neurons in the amygdala.

In summary, our studies provide novel insight into the relationship between embryonic telencephalic patterning and limbic system formation. As disruption of the development of the limbic system is a hallmark feature of numerous neurodevelopmental disorders, most notably autism spectrum disorders (Rodrigues et al., 2004; Amaral et al., 2008; Herry et al., 2008; Markram et al.,
2008; Monk, 2008), it will be interesting to determine whether disrupted development of the telencephalic pallial-subpallial boundary is a common feature of such disorders. Indeed, $T l x$ mutant mice, which have a disrupted vP PSB domain and amygdala abnormalities, have increased aggression, suggesting that the correct development of this boundary is necessary for the formation of amygdala fear circuitry (Roy et al., 2002; Stenman et al., 2003b). Further support for this link comes from a recent study of Pax6 heterozygote mutant rats $\left(r \mathrm{Sey}^{2} /+\right)$ which revealed alterations in both social behavior and fear conditioning (Umeda et al., 2010), two behaviors that involve the amygdala. Thus, understanding the long-term behavioral consequences of specific genetic disruptions of this embryonic boundary will prove highly informative.

\section{References}

Amaral DG, Schumann CM, Nordahl CW (2008) Neuroanatomy of autism. Trends Neurosci 31:137-145.

Batista-Brito R, Close J, Machold R, Fishell G (2008) The distinct temporal origins of olfactory bulb interneuron subtypes. J Neurosci 28:3966-3975.

Brill MS, Snapyan M, Wohlfrom H, Ninkovic J, Jawerka M, Mastick GS, Ashery-Padan R, Saghatelyan A, Berninger B, Götz M (2008) A dlx2and pax6-dependent transcriptional code for periglomerular neuron specification in the adult olfactory bulb. J Neurosci 28:6439-6452.

Carney RS, Alfonso TB, Cohen D, Dai H, Nery S, Stoica B, Slotkin J, Bregman BS, Fishell G, Corbin JG (2006) Cell migration along the lateral cortical stream to the developing basal telencephalic limbic system. J Neurosci 26:11562-11574.

Carney RS, Cocas LA, Hirata T, Mansfield K, Corbin JG (2009) Differential regulation of telencephalic pallial-subpallial boundary patterning by Pax6 and Gsx2. Cereb Cortex 19:745-759.

Cocas LA, Miyoshi G, Carney RS, Sousa VH, Hirata T, Jones KR, Fishell G, Huntsman MM, Corbin JG (2009) Emx1-lineage progenitors differentially contribute to neural diversity in the striatum and amygdala. J Neurosci 29:15933-15946.

Corbin JG, Gaiano N, Machold RP, Langston A, Fishell G (2000) The Gsx2 homeodomain gene controls multiple aspects of telencephalic development. Development 127:5007-5020.

Corbin JG, Rutlin M, Gaiano N, Fishell G (2003) Combinatorial function of the homeodomain proteins $\mathrm{Nkx2.1}$ and Gsx2 in ventral telencephalic patterning. Development 130:4895-4906.

Dellovade TL, Pfaff DW, Schwanzel-Fukuda M (1998) Olfactory bulb development is altered in small-eye (Sey) mice. J Comp Neurol 402:402-418.

Gal JS, Morozov YM, Ayoub AE, Chatterjee M, Rakic P, Haydar TF (2006) Molecular and morphological heterogeneity of neural precursors in the mouse neocortical proliferative zones. J Neurosci 26:1045-1056.

García-Moreno F, Pedraza M, Di Giovannantonio LG, Di Salvio M, LópezMascaraque L, Simeone A, De Carlos JA (2010) A neuronal migratory pathway crossing from diencephalon to telencephalon populates amygdala nuclei. Nat Neurosci 13:680-689.

Gong S, Zheng C, Doughty ML, Losos K, Didkovsky N, Schambra UB, Nowak NJ, Joyner A, Leblanc G, Hatten ME, Heintz N (2003) A gene expression atlas of the central nervous system based on bacterial artificial chromosomes. Nature 425:917-925.

Haba H, Nomura T, Suto F, Osumi N (2009) Subtype-specific reduction of olfactory bulb interneurons in Pax6 heterozygous mutant mice. Neurosci Res 65:116-121.

Herry C, Ciocchi S, Senn V, Demmou L, Müller C, Lüthi A (2008) Switching on and off fear by distinct neuronal circuits. Nature 454:600-606.

Hirata T, Li P, Lanuza GM, Cocas LA, Huntsman MM, Corbin JG (2009) Identification of distinct telencephalic progenitor pools for neuronal diversity in the amygdala. Nat Neurosci 12:141-149.

Jiménez D, López-Mascaraque L, de Carlos JA, Valverde F (2002) Further studies on cortical tangential migration in wild type and Pax-6 mutant mice. J Neurocytol 31:719-728.

Kaoru T, Liu FC, Ishida M, Oishi T, Hayashi M, Kitagawa M, Shimoda K, Takahashi H (2010) Molecular characterization of the intercalated cell masses of the amygdala: implications for the relationship with the striatum. Neuroscience 166:220-230. 
Kessaris N, Fogarty M, Iannarelli P, Grist M, Wegner M, Richardson WD (2006) Competing waves of oligodendrocytes in the forebrain and postnatal elimination of an embryonic lineage. Nat Neurosci 9:173-179.

Kohwi M, Osumi N, Rubenstein JL, Alvarez-Buylla A (2005) Pax6 is required for making specific subpopulations of granule and periglomerular neurons in the olfactory bulb. J Neurosci 25:6997-7003.

Kroll TT, O'Leary DD (2005) Ventralized dorsal telencephalic progenitors in Pax6 mutant mice generate GABA interneurons of a lateral ganglionic eminence fate. Proc Natl Acad Sci U S A 102:7374-7379.

Likhtik E, Popa D, Apergis-Schoute J, Fidacaro GA, Paré D (2008) Amygdala intercalated neurons are required for expression of fear extinction. Nature 454:642-645.

Lledo PM, Merkle FT, Alvarez-Buylla A (2008) Origin and function of olfactory bulb interneuron diversity. Trends Neurosci 31:392-400.

Markram K, Rinaldi T, La Mendola D, Sandi C, Markram H (2008) Abnormal fear conditioning and amygdala processing in an animal model of autism. Neuropsychopharmacology 33:901-912.

Mastick GS, Davis NM, Andrew GL, Easter SS Jr (1997) Pax-6 functions in boundary formation and axon guidance in the embryonic mouse forebrain. Development 124:1985-1997.

Monk CS (2008) The development of emotion-related neural circuitry in health and psychopathology. Dev Psychopathol 20:1231-1250.

Nery S, Fishell G, Corbin JG (2002) The caudal ganglionic eminence is a source of distinct cortical and subcortical cell populations. Nat Neurosci 5:1279-1287.

Nomura T, Holmberg J, Frisen J, Osumi N (2006) Pax6-dependent boundary defines alignment of migrating olfactory cortex neurons via the repulsive activity of ephrin A5. Development 133:1335-1345.

Nomura T, Haba H, Osumi N (2007) Role of a transcription factor Pax6 in the developing vertebrate olfactory system. Dev Growth Differ 49:683-690.

Rodrigues SM, Schafe GE, LeDoux JE (2004) Molecular mechanisms underlying emotional learning and memory in the lateral amygdala. Neuron 44:75-91.

Roy K, Thiels E, Monaghan AP (2002) Loss of the tailless gene affects forebrain development and emotional behavior. Physiol Behav 77:595-600.

Sah P, Lopez De Armentia M (2003) Excitatory synaptic transmission in the lateral and central amygdala. Ann N Y Acad Sci 985:67-77.

Sah P, Faber ES, Lopez De Armentia M, Power J (2003) The amygdaloid complex: anatomy and physiology. Physiol Rev 83:803-834.

Simpson TI, Pratt T, Mason JO, Price DJ (2009) Normal ventral telence- phalic expression of Pax6 is required for normal development of thalamocortical axons in embryonic mice. Neural Dev 4:19.

Stenman J, Toresson H, Campbell K (2003a) Identification of two distinct progenitor populations in the lateral ganglionic eminence: implications for striatal and olfactory bulb neurogenesis. J Neurosci 23:167-174.

Stenman J, Yu RT, Evans RM, Campbell K (2003b) Tlx and Pax6 co-operate genetically to establish the pallio-subpallial boundary in the embryonic mouse telencephalon. Development 130:1113-1122.

Stoykova A, Fritsch R, Walther C, Gruss P (1996) Forebrain patterning defects in Small eye mutant mice. Development 122:3453-3465.

Stoykova A, Götz M, Gruss P, Price J (1997) Pax6-dependent regulation of adhesive patterning, R-cadherin expression and boundary formation in developing forebrain. Development 124:3765-3777.

Talamillo A, Quinn JC, Collinson JM, Caric D, Price DJ, West JD, Hill RE (2003) Pax6 regulates regional development and neuronal migration in the cerebral cortex. Dev Biol 255:151-163.

Tole S, Remedios R, Saha B, Stoykova A (2005) Selective requirement of Pax6, but not Emx2, in the specification and development of several nuclei of the amygdaloid complex. J Neurosci 25:2753-2760.

Toresson H, Potter SS, Campbell K (2000) Genetic control of dorsal-ventral identity in the telencephalon: opposing roles for Pax6 and Gsx2. Development 127:4361-4371.

Umeda T, Takashima N, Nakagawa R, Maekawa M, Ikegami S, Yoshikawa T, Kobayashi K, Okanoya K, Inokuchi K, Osumi N (2010) Evaluation of Pax6 mutant rat as a model for autism. PLoS One 21:e15500.

Waclaw RR, Allen ZJ 2nd, Bell SM, Erdélyi F, Szabó G, Potter SS, Campbell K (2006) The zinc finger transcription factor Sp8 regulates the generation and diversity of olfactory bulb interneurons. Neuron 49:503-516.

Waclaw RR, Wang B, Pei Z, Ehrman LA, Campbell K (2009) Distinct temporal requirements for the homeobox gene Gsx2 in specifying striatal and olfactory bulb neuronal fates. Neuron 63:451-465.

Waclaw RR, Ehrman LA, Pierani A, Campbell K (2010) Developmental origin of the neuronal subtypes that comprise the amygdalar fear circuit in the mouse. J Neurosci 30:6944-6953.

Young KM, Fogarty M, Kessaris N, Richardson WD (2007) Subventricular zone stem cells are heterogeneous with respect to their embryonic origins and neurogenic fates in the adult olfactory bulb. J Neurosci $27: 8286-8296$

Yun K, Potter S, Rubenstein JL (2001) Gsx2 and Pax6 play complementary roles in dorsoventral patterning of the mammalian telencephalon. Development 128:193-205. 